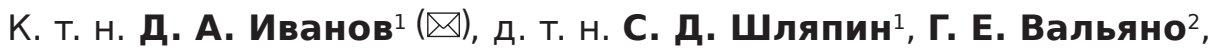
К. Т. Н. Л. В. Федорова

${ }^{1}$ Московский авиационный институт (национальный исследовательский университет), Москва, Россия

2 ФГБУН «Объединенный институт высоких температур РАН», Москва, Россия

\title{
УДК 666.3-127:546.62-31
}

\section{СТРУКТУРА И ФИЗИКО-МЕХАНИЧЕСКИЕ СВОЙСТВА ПОРИСТОЙ КЕРАМИКИ НА ОСНОВЕ $\mathrm{Al}_{2} \mathrm{O}_{3}$, ПОЛУЧЕННОЙ С ИСПОЛЬЗОВАНИЕМ МЕТОДА ФИЛЬТРАЦИОННОГО ГОРЕНИЯ}

Предложен технологический подход, позволяющий получать высокопористую керамику на основе $\mathrm{Al}_{2} \mathrm{O}_{3}$ С использованием метода фильтрационного горения (ФГ). В основе метода лежит экзотермическая реакция окисления (в режиме ФГ) частиц алюминиевой пудры ПАП-2, смешиваемой со сферолитами технического глинозема (1-й тип материала) или каолиновыми волокнами (2-й тип материала). В зависимости от объемной доли ПАП-2 открытая пористость спеченного материала 1-го типа от 38 до 50 \%, а предел прочности при изгибе от 10 до 50 МПа. Высокая термостойкость материала, оцениваемая по относительной потере трещиностойкости после термоцикла в режиме нагрев при $850{ }^{\circ} \mathrm{C}-$ охлаждение воздушной струей $\left(1{ }^{\circ} \mathrm{C}\right)$, составляла $12-15 \%$ и не изменялась после пяти последовательных термо-

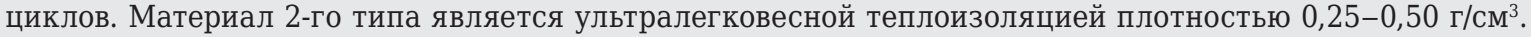
Прочность на смятие 0,10-0,15 МПа, теплопроводность в интервале от 20 до $1000{ }^{\circ} \mathrm{C} 0,06-0,17 \mathrm{BT} /(\mathrm{м} \cdot \mathrm{K})$.

Ключевые слова: пористая алюмооксидная керамика, самораспространяющийся высокотемпературный синтез (СВС), метод фильтрационного горения (ФГ), порошковая заготовка (ПЗ), ультралегковесная теплоизолящия.

\section{ВВЕДЕНИЕ}

$\Pi$ ористые керамические материалы на основе $\mathrm{Al}_{2} \mathrm{O}_{3}$ находят широкое применение в высокотемпературной технике, например в качестве термостойких элементов конструкций, теплоизоляционных изделий и фильтров газовых и жидких сред [1-4]. Создание порового пространства в материале может достигаться обычными приемами, например применением выгорающих добавок, реализацией пенометода, а также за счет формования изделия из волокон или пустотелых сферических частиц - микробаллонов [5].

В работе [6] показана возможность создания значительной пористости в алюмооксидном материале в результате использования эффекта зонального уплотнения при спекании порошковых заготовок (П3), состоящих из частиц наноразмерного диапазона. Кроме того, для получения пористых огнеупорных материалов и теплоизоляции разработана новая технология, сочетающая холодное вспучивание и процесс самораспространяющегося высокотемпера-

\section{$凶$}

Д. А. Иванов

E-mail: dali_888@mail.ru турного синтеза (СВС), обеспечивающий так называемый «термохимический синтез» и спекание образующихся фаз за счет тепла экзотермических реакций [7]. Известен также метод реакционного спекания в режиме фильтрационного горения (ФГ) на воздухе ПЗ из алюминиймагниевого сплава для изготовления кермета $\mathrm{MgO}-\mathrm{Al}$ [8], позволяющий получать высокопористые изделия. Этот технологический подход может рассматриваться как разновидность CBC-метода, в котором зажигание ПЗ достигается в результате обтекания ее поверхности горячим (550-600 $\left.{ }^{\circ} \mathrm{C}\right)$ воздушным теплоносителем в объеме печного пространства. При этом ФГ поддерживается вследствие возникающего перепада парциального давления кислорода воздуха, содержащегося внутри системы сообщающихся открытых пор ПЗ и обтекающего ПЗ. При этом реализуется всасывание (фильтрация) воздуха внутрь объема заготовки. Следует отметить, что в спеченном материале сохраняется значительная доля неокисленного алюминия благодаря защитному действию плотных алюмооксидных пленок на его поверхности.

В рамках настоящей работы изучали особенности структуры и физико-механические свойства пористой керамики на основе $\mathrm{Al}_{2} \mathrm{O}_{3}$, полученной с использованием метода ФГ. 


\section{МЕТОДИКА ЭКСПЕРИМЕНТА И ИССЛЕДОВАНИЯ}

В качестве исходных материалов использовали порошок технического глинозема марки Г-00 (ГОСТ 30558), частицы которого имеют сферолитное строение, а также каолиновые волокна (ГОСТ 23619) и алюминиевую пудру марки ПАП-2 (ГОСТ 5494) с чешуйчатой формой частиц субмикронной толщины. Предварительно сферолиты технического глинозема подвергали термообработке на воздухе при $1350{ }^{\circ} \mathrm{C}$ в течение 1 ч для завершения модификационного перехода $\gamma-\mathrm{Al}_{2} \mathrm{O}_{3} \rightarrow \alpha-\mathrm{Al}_{2} \mathrm{O}_{3}$, сопровождающегося уменьшением объема примерно на $14 \%$.

Для изготовления образцов алюминиевую пудру в количестве 30-70 об. \% смешивали со сферолитами и полученную смесь прессовали под давлением 200 МПа (1-й тип П3). Также из каолиновых волокон готовили водную суспензию, в которую при непрерывном перемешивании вводили алюминиевую пудру (10-30 об. \%). Затем из полученной смеси откачивали жидкость путем вакуумной фильтрации и высушивали полученную заготовку на воздухе (2-й тип П3). Оба типа П3 нагревали на воздухе до температуры 500-550 $\mathrm{C}$, при которой инициировался процесс ФГ. После его завершения нагрев продолжали до $1500{ }^{\circ} \mathrm{C}$ с последующей изотермической выдержкой в течение 1 ч, обеспечивающей полное окисление металлического компонента. При этом получали два типа спеченных материалов, содержащих сферолиты (1-й тип) и каолиновые волокна (2-й тип).

Материал 1-го типа испытывали на термостойкость, оценивая величину относительной потери трещиностойкости образцов с надрезом после воздействия термических напряжений [9], используя установку локального термоудара [10]. В этом случае термические напряжения у вершины надреза создавали путем термоциклирования по режиму: нагрев на воздухе при $850{ }^{\circ} \mathrm{C}-$ охлаждение воздушной струей $\left(18{ }^{\circ} \mathrm{C}\right)$. Относительную потерю трещиностойкости рассчитывали по формуле $\left(1-K_{\mathrm{Ic}}^{\mathrm{T}} / K_{\mathrm{Ic}}\right) \cdot 100 \%$, где $K_{\mathrm{Ic}}$ и $K_{\mathrm{Ic}}^{\mathrm{T}}-$ значения критических коэффициентов интенсивности напряжений для образцов до и после термоцикла соответственно. Предел прочности при изгибе определяли на призматических образцах размерами $8 \times 8 \times 50$ мм, используя трехточечную схему нагружения при скорости деформирования 1 мм/мин. у материала 2-го типа определяли напряжение смятия при сжатии цилиндрических образцов диаметром 20 и высотой 50 мм при скорости деформирования 0,1 мм/мин. Кроме того, измеряли показатель эффективной теплопроводности в интервале 20-1000 ${ }^{\circ} \mathrm{C}$ методом горячей проволоки в условиях стационарного теплового потока с применением измерительного креста (ISO 8894-1).

Фазовый состав материалов исследовали с применением рентгенофазового анализа (РФА) на установке ДРОН-3 (излучение $\mathrm{Cu} K_{\alpha}$ ) по стандартной методике, структуру - на электронном микроcкопе «Hitachi-F405A» с поверхности излома образцов, полученной после механических испытаний. Плотность $\rho$ спеченных образцов рассчитывали как отношение их массы к объему. Общую пористость рассчитывали из соотношения $(1-\rho / \gamma) \cdot 100 \%$, где $\gamma=3,99$ г/см³. Открытую пористость определяли методом гидростатического взвешивания.

\section{ОБСУЖДЕНИЕ РЕЗУЛЬТАТОВ}

Пористые керамические материалы получали методом ФГ. Его продолжительность для образцов материала 1-го типа 7-10 мин, для материала 2-го типа 3-5 мин. В первом случае зафиксирована максимальная яркостная температура $1200^{\circ} \mathrm{C}$, во втором $1500{ }^{\circ} \mathrm{C}$.

На начальной стадии процесса ФГ происходит синтез $\mathrm{Al}_{2} \mathrm{O}_{3}$-фазы вследствие экзотермической реакции в системе расплав $(\mathrm{Al})$ - газ $\left(\mathrm{O}_{2}\right)$ в результате диффузии кислорода через поверхностные алюмооксидные пленки чешуйчатых частиц $\mathrm{k}$ алюминиевому расплаву. Прочность таких пленок достаточна для удерживания перегретого алюминиевого расплава при температуре ФГ. Завершение ФГ образцов связано, по-видимому, с формированием плотной сетки из наноразмерных алюмооксидных кристаллов на поверхности алюминиевых чешуйчатых частиц, которые ее пассивируют, делая неактивной и непроницаемой для газообразного окислителя - кислорода воздуха. В этом случае алюминиевые чешуйки оказываются внутри плотных алюмооксидных капсул.

Как видно по результатам РФА (табл. 1), добиться полного окисления алюминия в составе материала 1-го типа удалось только после его дополнительной термообработки на воздухе (по завершении ФГ) при $1500{ }^{\circ} \mathrm{C}$ в течение 1 ч. В данных условиях диффузионная активность атомарного кислорода становится достаточной для проникновения через алюмооксидные капсулы чешуйчатых частиц и полного окисления металла. На рис. 1 показаны пластинчатые алюмооксидные частицы $\left(\alpha-\mathrm{Al}_{2} \mathrm{O}_{3}\right)$ в структуре полученного материала, которые наследуют форму исходных чешуйчатых частиц пудры ПАП-2. Материал при значительной пористости $\left(\Pi_{\text {отк }}=38 \div 50 \%\right)$

Таблица 1. Фазовый состав материала 1-го типа ( $V=70$ об. \%) в зависимости от режима термообработки на воздухе

\begin{tabular}{|c|c|c|c|c|c|c|}
\hline \multicolumn{2}{|c|}{ Режим термообработки } & \multicolumn{4}{|c|}{ Содержание кристаллической фазы, об. \% } & \multirow{2}{*}{$\begin{array}{c}\text { Содержание аморфной } \\
\text { фазы, об. \% }\end{array}$} \\
\hline температура, ${ }^{\circ} \mathrm{C}$ & время, ч & $\mathrm{Al}$ & $\gamma-\mathrm{Al}_{2} \mathrm{O}_{3}$ & $\theta-\mathrm{Al}_{2} \mathrm{O}_{3}$ & $\alpha-\mathrm{Al}_{2} \mathrm{O}_{3}$ & \\
\hline 800 & 1 & 50 & 40 & 6 & - & 4 \\
\hline 1200 & 1 & 4 & - & - & 96 & - \\
\hline 1500 & 1 & - & - & - & 100 & - \\
\hline
\end{tabular}




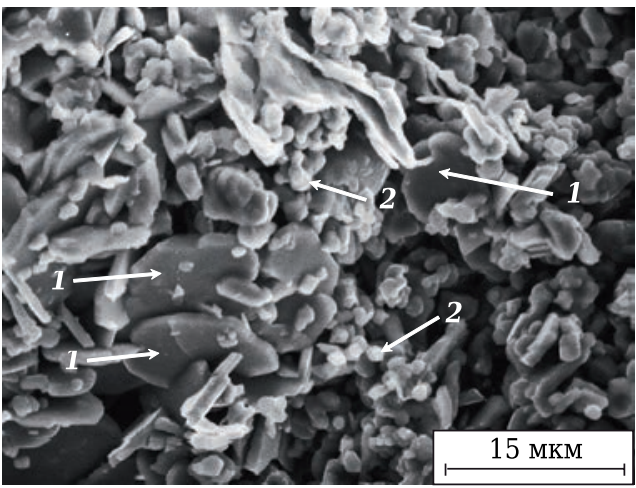

Рис. 1. Поверхность излома материала 1-го типа: $1-$ пластинчатые алюмооксидные частицы; 2 - алюмооксидные кристаллы в составе сферолита

имеет достаточно высокую прочность $\left(\sigma_{\text {изг }}=10 \div 50\right.$ МПа), которая увеличивается с возрастанием объемной доли ( $V, \%)$ алюминиевой пудры в исходной смеси со сферолитами (табл. 2). Такая закономерность объясняется армирующим действием пластинчатых алюмооксидных частиц, образующих непрерывный каркас, воспринимающий приложенную нагрузку. При этом наблюдается незначительная потеря трещиностойкости после термоудара благодаря быстрому устранению температурного градиента на элементах структуры, имеющих микронное сечение. Следует отметить, что показатель потери трещиностойкости материала 1-го типа не изменялся и после пяти последовательных термоциклов, тогда как у плотного алюмооксидного материала (№ 4, см. табл. 2) наблюдалось существенное снижение трещиностойкости после однократного термоцикла в результате действия термических напряжений, приводящих к образованию микротрещин в его структуре.

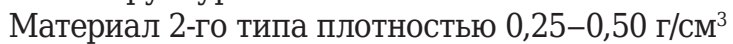
относится к классу ультралегковесной теплоизоляции (табл. 3). Напряжения, соответствующие начальному моменту смятия, возрастают с увеличением объемной доли алюминиевой пудры в смеси с каолиновыми волокнами. В этом случае наблюдается также эффект армирования структуры пластинчатыми алюмооксидными частицами (аналогично материалу 1-го типа). В структуре материала связывание каолиновых волокон достигается путем перекрытия их алюмооксидными пластинчатыми и каплеподобными частицами в результате припекания по областям контакта (рис. 2). Следует отметить, что формирование частиц 3 (см. рис. 2) происходит на стадии ФГ: агломераты из наночастиц пылевидной
Таблица 3. Зависимость физико-механических свойств материала от объемной доли $(V, \%)$ алюминиевой пудры в смеси с каолиновыми волокнами (2-й тип материала)

\begin{tabular}{|c|c|c|c|c|}
\hline $\begin{array}{c}\text { Номер } \\
\text { материала }\end{array}$ & $V$, об. \% & $\rho, \Gamma / \mathrm{CM}^{3}$ & $\Pi_{\text {общ, }} \%$ & $\begin{array}{l}\text { Прочность на } \\
\text { смятие, МПа }\end{array}$ \\
\hline 1 & 10 & 0,25 & 93 & 0,10 \\
\hline 2 & 20 & 0,40 & 90 & 0,12 \\
\hline 3 & 30 & 0,50 & 88 & 0,15 \\
\hline
\end{tabular}

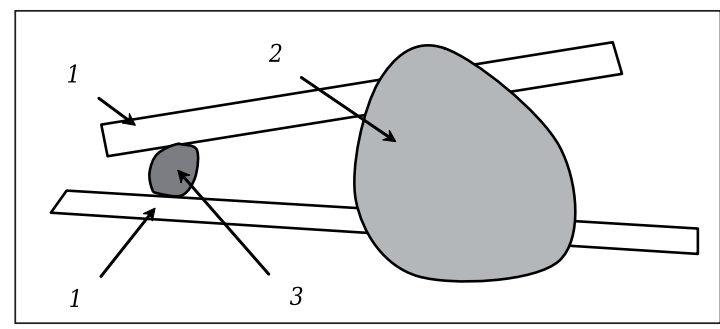

Рис. 2. Схематическое изображение связывания каолиновых волокон в объеме образца теплоизоляции: 1 каолиновые волокна; 2 - пластинчатая алюмооксидная частица; 3 - алюмооксидная каплеподобная частица

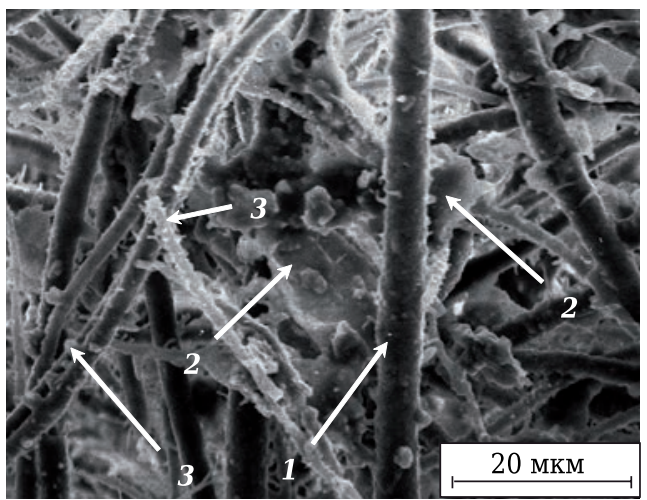

Рис. 3. Поверхность излома материала 2-го типа: 1 каолиновые волокна; 2 - алюмооксидные пластинчатые частицы, перекрывающие волокна; 3 - алюмооксидные каплеподобные частицы, перекрывающие волокна

фракции, содержащейся в пудре ПАП-2, при перегреве выше температуры плавления алюминия образуют «сидячие» капли с характерной формой из-за ограниченного смачивания поверхности каолиновых волокон. Такой механизм связывания каолиновых волокон в объеме образцов подтверждается при рассмотрении их поверхности излома после механических испытаний (рис. 3).

Разработанная ультралегковесная теплоизоляция демонстрирует относительно невысокую теплопроводность - 0,06-0,17 Вт/(м·К) в интервале от 20 до

Таблица 2. Зависимость физико-механических свойств материала от объемной доли алюминиевой пудры в смеси со сферолитами (материал 1-го типа)

\begin{tabular}{|c|c|c|c|c|c|c|}
\hline $\begin{array}{c}\text { Номер } \\
\text { материала }\end{array}$ & $V$, об. \% & $\rho, \Gamma / \mathrm{CM}^{3}$ & $\Pi_{\text {отк }}, \%$ & $\sigma_{\text {изг }}$, МПа & $K_{1 c}^{T} / K_{1 c}$, отн. ед. & $\left(1-K_{1 c}^{T} / K_{1 c}\right) \cdot 100, \%$ \\
\hline 1 & 30 & 1,9 & 50 & $10-20$ & $0,7 / 0,8$ & 12,5 \\
\hline 2 & 50 & 2,1 & 42 & $22-28$ & $1,3 / 1,5$ & 14,0 \\
\hline 3 & 70 & 2,3 & 38 & $30-50$ & $1,7 / 2,0$ & 15,0 \\
\hline $4^{*}$ & - & 3,8 & 0 & $250-300$ & $1,5 / 4,0$ & 62,5 \\
\hline
\end{tabular}


$1000{ }^{\circ} \mathrm{C}$, что можно объяснить экранирующим действием пластинчатых $\mathrm{Al}_{2} \mathrm{O}_{3}$-частиц, расположенных нормально по отношению к тепловому потоку. Зависимость теплопроводности $\lambda$ материала 2-го типа $(V=20$ об. \%) от температуры $T$ приведена ниже:

$$
\begin{array}{lcccccc}
T,{ }^{\circ} \mathrm{C} \ldots \ldots \ldots \ldots . . & 20 & 200 & 400 & 600 & 800 & 1000 \\
\lambda, \mathrm{BT} /(\mathrm{M} \cdot \mathrm{K}) . . & 0,06 & 0,08 & 0,09 & 0,10 & 0,12 & 0,17
\end{array}
$$

\section{ЗАКЛЮЧЕНИЕ}

Для получения пористых керамических материалов на основе $\mathrm{Al}_{2} \mathrm{O}_{3}$ был использован метод ФГ на воздухе П3, состоящих из смеси алюминиевой пудры ПАП-2 со сферолитами технического глинозема (1-й тип материала) и с каолиновыми волокнами (2-й тип материала). После окончания ФГ образцы дополнительно термообрабатывали на воздухе при $1500{ }^{\circ} \mathrm{C}$ в течение 1 ч для завершения процесса окисления алюминия. При этом из алюминиевых чешуйчатых частиц синтезируются пластинчатые алюмооксидные частицы $\left(\alpha-\mathrm{Al}_{2} \mathrm{O}_{3}\right)$, наследующие форму исходных алюминиевых чешуек.

Установлено, что у материала 1-го типа при варьировании объемной доли пудры ПАП-2 от 30 до 70 об. \% в смеси со сферолитами открытая пористость снижается от 50 до 38 \%, а предел прочности при изгибе возрастает от 10-20 до 30-50 МПа. Это связано с армирующим действием пластинчатых алюмооксидных частиц, которые формируют

\section{Библиографический список}

1. Зубащенко, Р. В. Термостойкие высокотемпературные теплоизоляционные изделия на основе алюмосиликатного волокна / Р. В. Зубащенко // Новые огнеупоры. - 2016. - № 12. - С. 3-5.

2. Зубащенко, Р. В. Футеровка малогабаритной туннельной печи высокоглиноземистыми изделиями на основе алюмосиликатного волокна / Р. В. Зубащенко // Новые огнеупоры. - 2017. - № 2. - С. 3-5.

3. Мокчаро, А. Пористая структура керамического материала, изготовленного с применением порообразующих добавок / А. Мокчаро, М. Б. Ломбарди, А. H. Шан // Новые огнеупоры. - 2017. - № 1. - С. 54-57.

Mocciaro, A. Ceramic material porous structure prepared using pore-forming additives / A. Mocciaro, $M$. B. Lombardi, A. N. Scian // Refractories and Industrial Ceramics. - 2017. — Vol. 58, № 1. - P. 65-68.

4. Беляков, А. В. Упрочняющие связующие для пористой проницаемой керамики с заполнителем из электроплавленого корунда / А. В. Беляков, Зо Е Мо У, Н. А. Попова [и др.] // Новые огнеупоры. - 2017. - № 2. - С. 25-29.

Belyakov, A. V. Strengthening Binders for Porous Permeable ceramic with Electromelted Corundum Filler / A. V. Belyakov, Zaw Ye Maw Oo, N. A. Popova [et al.]// Refractories and Industrial Ceramics. - 2017. - Vol. 58, № 1. - P. 89-93.

5. Химическая технология керамики : уч. пособие для вузов ; под ред. И. Я. Гузмана. - М. : РИФ «Стройматериалы», 2003. - 496 с.

6. Пат. 2522487 РФ МПК С 04 В 35/111, 35/626. Способ получения конструкционной алюмооксидной керамики / Баринов С. М., Дёмин В. А., Иванов А. В., Иванов Д. А., Омаров А. Ю., Шляпин А. Д., Шляпин непрерывный каркас, воспринимающий приложенную нагрузку. У материала 1-го типа зафиксирована незначительная потеря трещиностойкости (12-15 \%) после термоцикла по режиму нагрев при $850{ }^{\circ} \mathrm{C}$ - охлаждение воздушной струей с температурой $18{ }^{\circ} \mathrm{C}$ (этот показатель не изменялся и после пяти последующих термоциклов). Данный факт возможен благодаря быстрому устранению температурного градиента на элементах структуры, имеющих микронное сечение.

Материал 2-го типа плотностью 0,25-0,50

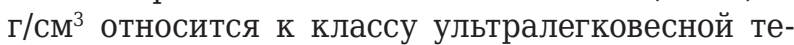
плоизоляции. Его плотность возрастает с увеличением объемной доли алюминиевой пудры (10--30 \%) в смеси с каолиновыми волокнами, напряжение смятия при воздействии сжимающей нагрузки составляет 0,10-0,15 МПа. Невысокая теплопроводность полученной теплоизоляции 0,06-0,17 Вт/(м·K) в интервале от 20 до $1000{ }^{\circ} \mathrm{C}$ объясняются экранирующим действием пластинчатых $\mathrm{Al}_{2} \mathrm{O}_{3}$-частиц, располагающихся нормально по отношению к тепловому потоку.

$$
* * *
$$

Исследования выполнены в рамках базовой части государственного задания вузам №11.7568.2017/ Б4 с использованием оборудования ресурсного центра коллективного пользования «Авиационнокосмические материалы и технологии» МАИ.

С. Д. - № 2012146829/03 ; заявл. 02.11 .12 ; опубл. 20.07.14, Бюл. № 20.

7. Владимиров, В. С. Новые огнеупорные и теплоизоляционные материалы и технологии их производства / В. С. Владимиров, А. П. Галаган, М. А. Илюхин [и др.] // Новые огнеупоры. - 2002. - № 1 (апрель). - С. 81-88.

8. Васин, А. А. Исследование процесса синтеза керметов из порошков, полученных химическим диспергированием Al-Mg (20 мас. \%)-сплава / А. А. Васин, B. П. Тарасовский. А. Ю. Омаров, В. В. Рыбалченко // Новые огнеупоры. - 2015. - № 6. - С. 62-65.

Vasin, A. A. Stady of cermet synthesis from powders prepared by chemical dispersion of $\mathrm{Al}-\mathrm{Mg}$ (20 wt. \%)alloy / A. A. Vasin, V. P. Tarasovskii, A. Yu. Omarov, V. V. Rybalchenco // Refractories and Industrial Ceramics. 2015. - Vol. 56, № 3. - P. 310-314.

9. Иванов, Д. А. Оценка термостойкости конструкционной керамики при испытании призматических образцов с надрезом / Д. А. Иванов, А. И. Ситников, Г. Е. Вальяно // Стекло и керамика. - 2001. - № 5. - С. 14-18.

Ivanov, D. A. Evaluation of the thermal resistance of structural ceramics in testing notched prismatic samples / D. A. Ivanov, A. I. Sitnikov, G. E. Val'yano // Glass and Ceramics. - 2001. - Vol. 58, № 5/6. - P. 169-173.

10. Иванов, Д. А. Особенности разрушения керамических материалов при термическом нагружении методом локального термоудара / Д. А. Иванов, А. И. Ситников // Огнеупоры и техническая керамика. -2004 . - № 12. C. 30-35.

Получено 24.05.17 (ㄷ Д. А. Иванов, С. Д. Шляпин, Г. Е. Вальяно, Л. В. Федорова, 2017 г. 